\title{
Del control previo y perceptivo al posterior y preventivo: estudio de la trayectoria en el control fiscal en Colombia (1991-2019)*
}

\author{
From prior and perceptual control to subsequent and preventive: study \\ of the course of fiscal control in Colombia (1991-2019)
}

\author{
Alexandra González Zapata* \\ Leyner Mosquera Perea ${ }^{* * *}$
}

Fecha de recepción: 2 de octubre del 2019

Fecha de aprobación: 5 de diciembre del 2019

\section{RESUMEN}

La Asamblea Nacional Constituyente de Colombia de 1991 discutió de manera profunda el funcionamiento del control fiscal en el nuevo Estado social de derecho. Propuso varias modificaciones, la más importante de las cuales fue pasar del control previo y perceptivo al posterior y selectivo. No obstante, veintiocho ańos después, los organismos de control alertaron sobre los límites de esta figura y entonces, a través del poder legislativo, se creó

\footnotetext{
Este artículo es producto del proyecto de investigación "Observatorio de Política Pública de Control Fiscal
} (ортст)", gestionado en la Auditoría General de la República.

Citar como González Zapata, A. y Mosquera, L. (2020). Del control previo y perceptivo al posterior y preventivo: estudio de la trayectoria en el control fiscal en Colombia 1991-2019. Via Inveniendi et Iudicandi, 15(1), 71-90. DoI: https://doi.org/10.15332/19090528/5742

* Politóloga y magíster en Políticas Públicas de la Universidad Nacional de Colombia. Docente en el área de investigación del departamento de Derecho de la misma Universidad. Experiencia en análisis de política pública, política criminal y derechos humanos. Investigadora de la Escuela de Investigación en Criminología Mediática, Justica Penal y Política Criminal Luis Carlos Pérez de la Universidad Nacional de Colombia y del Observatorio de Política Pública del Control Fiscal Adscrito, según convenio, a la Auditoría General de la República. Correo: apgonzalezz@unal.edu.co oRcid: 0000-0002-6016-7123.

*.* Leyner Mosquera Perea, ingeniero de Producción Industrial y candidato a magíster en Economía Aplicada de la Universidad de los Andes. Asesor del despacho de la Dirección Nacional de la Escuela Superior de Administración Pública (ESAP); investigador del Semillero Pacífico de la Facultad de Economía de la Universidad de los Andes e investigador del Observatorio de Política Pública del Control Fiscal adscrito, según convenio, a la Auditoría General de la República. Correo: 1.mosquera@uniandes.edu.co ORCiD: 0000-0001-8431-3482. 


\title{
VIeI Revista Virtual
}

Via Inveniendi et Iudicandi

la figura del control preventivo. Este artículo analiza esta trayectoria y las trasformaciones que esto ha generado en la política de control fiscal en Colombia, identificando los retos y aspectos relevantes para que esta figura opere sin que se anteponga al control interno.

Palabras clave: control fiscal, control previo, control posterior, control preventivo, Constitución de 1991.

\begin{abstract}
Colombia's 1991 National Constituent Assembly discussed in depth the functioning of fiscal control in the new social State of law. It proposed several modifications, with moving from prior and perceptual control to subsequent and selective control as the most important one. However, twenty-eight years later, the control agencies warned about the limits of this figure and, through the legislature, the preventive control figure was created. This article analyzes this course and the transformations that this has generated in the fiscal control policy in Colombia, identifying the challenges and relevant aspects so that this figure operates without being placed above internal control.
\end{abstract}

Key words: fiscal control, prior control, subsequent control, preventive control, 1991 Constitution. 


\section{INTRODUCCIÓN}

La Asamblea Nacional Constituyente y la Constitución Política de 1991 fueron la síntesis de un proceso de trasformación que años atrás venía reformulando los principios sobre los cuales se había edificado el Estado colombiano (Rodríguez, 2014).

La Carta Magna de 1991 pretendió, entre otros aspectos, reorientar los órganos que se articulaban a partir de distintas funciones (disciplinaria, fiscal, penal, contable, entre otras) a la política de control fiscal en el país a la vez que creó nuevas entidades como la Fiscalía General de la Nación (1991), la Contaduría General de la Nación (1996) y la Auditoría General de la Republica (1992) y reformulando el carácter y el mandato legal de otras que existían en el país desde hacía décadas, como la Procuraduría General de la Nación (1819) y la Contraloría General de la República (1923).

Siguiendo la tradición latinoamericana que desató una oleada de reformismo y reformulación constitucional desde la década de los ochenta, la Asamblea Nacional Constituyente buscó "reforzar las instancias estatales de control, fortaleciendo la autonomía y la capacidad fiscalizadora de las mismas” (Uprimny, 2011, p. 118).

La Asamblea tuvo cinco comisiones permanentes que se ocuparon de diversos temas. Comisión primera: principios, derechos, deberes y garantías fundamentales, mecanismos e instituciones de protección, participación democrática, sistema electoral, partidos políticos, estatuto de la oposición, reformas a la Constitución. Comisión segunda: ordenamiento territorial del Estado, autonomía regional y local. Comisión tercera: gobierno y congreso, hacienda pública y control fiscal. Comisión cuarta: administración de justicia y ministerio público. Comisión quinta: asuntos económicos, sociales, de hacienda y control fiscal.

A pesar de esta separación, se desplegaron propuestas y debates relativos al control fiscal en las cinco comisiones de trabajo. En total, el Observatorio de Política Pública de Control Fiscal (ОРPCF) de la Auditoría General de la República identificó 35 propuestas sobre el control fiscal presentadas en la Asamblea Nacional Constituyente (González, 2018); de estas, 11 abordaban la estructura y mandato del control fiscal, de las cuales se resaltaba la propuesta de pasar de un control previo y perceptivo a uno posterior y selectivo. 
Después, el poder legislativo abordó el desarrollo normativo que la Constitución había plasmado sobre el control fiscal. Así, se promulgó en 1993 la Ley 42 por medio de la cual se organiza el sistema de control fiscal financiero y los organismos que lo ejercen. Allí se estableció que "el control fiscal es una función pública, la cual vigila la gestión fiscal de la administración y de los particulares o entidades que manejen fondos o bienes del Estado en todos sus órdenes y niveles" (Congreso de la República, 1993a, artículo 4). Además, se determinó que este ejercicio sería de forma posterior y selectiva.

Sin embargo, durante los más de 28 años de funcionamiento, los organismos de control detectaron dificultades en lo que se consagró como la principal innovación de la Constitución de 1991 para evitar la coadministración. Así, el 27 de marzo del 2019 el contralor general de la República Carlos Felipe Córdoba presentó un proyecto de acto legislativo para modificar constitucionalmente el control fiscal, en particular, para adicionarle al control posterior uno preventivo.

Este proyecto fue aprobado e incorporado a nuestro ordenamiento y texto constitucional el 18 de septiembre del presente año (2019). Con él se cierra un ciclo del control fiscal en Colombia y se inicia una nueva etapa que permitirá determinar si los cambios dados permitieron garantizar el cumplimiento de los principios de la gestión fiscal: eficiencia, economía, eficacia, equidad y valoración de costos ambientales.

Este artículo pretende identificar los fundamentos constitucionales y legales del control fiscal para establecer cuál fue el horizonte que se le pretendió dar a esta función pública y así comprender si los cambios presentados posteriormente se deben a un proceso de actualización, reformulación o trasformación de lineamientos. Lo anterior, a través de un método de análisis documental que establece un análisis histórico. Esto permitirá establecer trayectorias del control fiscal en Colombia y gestionar la información relativa a las reformas actuales, a la vez que crea insumos efectivos para la toma de decisiones de las autoridades competentes sobre esta materia.

\section{LOS FUNDAMENTOS CONSTITUCIONALES DEL CONTROL POSTERIOR}

En la Asamblea Nacional Constituyente se decidió excluir la figura del control previo ejercida por la Contraloría, que se aplicaba siguiendo lo dispuesto por la Ley 20 de 
1975 por considerarla ineficaz y nociva, dado que, según los imaginarios construidos, este procedimiento se había convertido en un sistema de coadministración arbitraria. Por esta razón, se decidió que el control fiscal debía ser posterior y selectivo (Blanco, 2013). Esto implicó abandonar el modelo de control previo que se había desarrollado en el país desde la segunda década del siglo xx. Según el poder constituyente,

el control previo, generalizado en Colombia, ha sido funesto para la administración pública pues ha desvirtuado el objetivo de la Contraloría al permitirle ejercer abusivamente una cierta coadministración que ha redundado en un gran poder unipersonal del contralor y se ha prestado también para una engorrosa tramitomanía que degenera en corruptelas. (Noriega, Gonzalez y Herrán, 1991)

El control previo fue considerado por la misión Kemmerer como un enfoque básico de control fiscal, a su vez que el control posterior. El primero perduró como único método durante casi 70 ańos. Pese a que los constituyentes consideraban que habían gestado una gran trasformación en el sistema de control fiscal colombiano al incluir la figura del control posterior, sus antecedentes se remontan a 1975, cuando la Ley 20 dio origen a los controles previo, perceptivo y posterior (control numérico legal) (Pavas, 2010, p. 84).

Sin embargo, dieciséis años después de esta ley, la Asamblea Nacional Constituyente decidió excluir las figuras del control previo y perceptivo por considerarlas ineficaces y nocivas, dado que se había convertido, según el imaginario social, en un sistema de coadministración arbitrario.

La Comisión tercera no tardó mucho en decidir que el control fiscal debía ser posterior y selectivo. Esto implicó abandonar el modelo de control previo que se había desarrollado en el país desde la segunda década del siglo xx. El cambio hacia un modelo de control posterior también implicaba, según algunos constituyentes, avanzar hacia el control de resultados, atendiendo a la necesidad de garantizar el logro de los resultados que la sociedad debe obtener de la utilización de los recursos estatales. No obstante, esta decisión no fue exenta de discusión y problematización por la Asamblea.

Un ejemplo de ello fue la propuesta de crear un departamento nacional de control de resultados impulsada por Jesús Pérez González-Rubio. Para él, el control fiscal y 
el control de resultados no deben estar a cargo de la misma institución, y menos de la contraloría, pues esta se consideraba una entidad burocratizada con una dinámica procedimental y no de resultados.

El constituyente propuso crear el Sistema de Control de Resultados de la Administración Pública Nacional como organismo del Estado, de naturaleza jurídica especial (González, 2016), cuyo objetivo fuese vigilar el cumplimiento del plan de desarrollo económico y social, de obras públicas y de la administración de justicia, así como de sus programas y proyectos y verificar los avances y resultados de estos en términos de tiempo, costos y prioridades. Se concibió este departamento como una institución que tuviera por lo menos la misma jerarquía de la Procuraduría o la Contraloría actual.

El control fiscal es muy distinto del control de resultados. El control fiscal refiere al presupuesto, se refiere a si el funcionario correspondiente encuadra sus gastos dentro del marco de autorizaciones que en otra cosa es el presupuesto aprobado por el Congreso, y así verificará si existe un crédito para determinado objetivo y verificará si la partida todavía alcanza para ejecutar el gasto, es lo que se conoce como el control numérico legal. El control de resultados, por el contrario, hace referencia a las acciones de la administración, a los planes y programas de desarrollo y contrasta los recursos con los resultados obtenidos y los resultados obtenidos con los objetivos y las metas preestablecidas de manera que estamos hablando de cosas que de común solo tienen la palabra control, fuera de eso no tienen en común absolutamente nada [...] creo que sería un grandísimo error, un error que probablemente si esta Constitución lo llegará a cometer, no se lo perdonaría en el futuro, pretender entregarle un instrumento nuevo de tanta importancia para lograr la eficiencia del Estado a una institución burocratizada, clientelizada, unos funcionarios que tienen una manera de actuar y una mentalidad determinada, eso es un nicho de clientelismo y vamos a esterilizar ese instrumento formidable del control de resultados. (Asamblea Nacional Constituyente, 1991, p. 23)

No obstante, el constituyente Alfonso Palacio Rudas consideró que no era conveniente una iniciativa de este alcance en razón de que estas funciones debían integrarse con las competencias del control fiscal. De igual forma se pronunció Zafra Roldan: 
Solo tengo observaciones digamos tangenciales sobre el sistema de control de resultados que se le asigna a Planeación Nacional pues lo que va a hacer es congestionar aún más a Planeación Nacional. Uno quiere una Planeación Nacional diseñando el futuro del país, pensando diez años hacia adelante y no revisando y auditando como se cumplieron los presupuestos de todo el país como aparentemente se diseńa aquí. Por lo demás, eso es una función de la Contraloría. Si estamos fortaleciendo la Contraloría, si la estamos llevando a control posterior y de resultados, pues yo no veo por qué se le va a quitar esa función desarticulando el ente de control. (Asamblea Nacional Constituyente, 1991, p. 80)

Finalmente, los constituyentes optaron por incluir el control de resultados dentro de la rama de control fiscal, atendiendo a que esta función no solo implicaba revisar que no se malversaran los recursos, sino que se utilizaran según los principios de economía eficiente y eficaz.

El control previo y perceptivo fue remplazado por el posterior y selectivo, que comprende los controles financiero, de gestión y de resultados basados en la eficiencia, la economía, la equidad y la valoración de los costos ambientales. Esta función se desarrolla en los artículos 267 y 272 de la Constitución Política (González, 2019).

El ejercicio del control fiscal en Colombia, según la Ley 42 de 1993, que desarrolla los principios establecidos en la Constitución Política, debe

determinar en la administración, en un período determinado, que la asignación de recursos sea la más conveniente para maximizar sus resultados; que en igualdad de condiciones de calidad los bienes y servicios se obtengan al menor costo; que sus resultados se logren de manera oportuna y guarden relación con sus objetivos y metas. Así mismo, que permita identificar los receptores de la acción económica y analizar la distribución de costos y beneficios entre sectores económicos y sociales y entre entidades territoriales y cuantificar el impacto por el uso o deterioro de los recursos naturales y el medio ambiente y evaluar la gestión de protección, conservación, uso y explotación de los mismos. (Sentencia C-103, 2015, p. 22) 
En el capítulo "Principios Constitucionales de la gestión fiscal: condiciones esenciales para garantizar los derechos fundamentales" del libro Presupuesto para la construcción de una politica pública del control fiscal, del Observatorio de Política Pública de Control Fiscal de la Auditoría General de la República (González, 2019, pp. 14-29), se señalan las principales trasformaciones y bases constitucionales del control fiscal vigente en el país. El texto constitucional de 1991, por su parte, definió los valores y principios que rigen actualmente el control fiscal. Para ello, en la Constitución Política de Colombia se estableció que la Contraloría General de la República (art. 267), las contralorías territoriales (art. 272) y la Auditoría General de la República (art. 274) realizan un proceso de vigilancia de la gestión fiscal.

La vigilancia de la gestión fiscal del Estado incluye el ejercicio de un control financiero, de gestión y de resultados, fundado en la eficiencia, la economía, la equidad y la valoración de los costos ambientales. En los casos excepcionales, previstos por la ley, la Contraloría podrá ejercer control posterior sobre cuentas de cualquier entidad territorial. (Constitución Política, art. 267)

El artículo 5. de la Ley 42 de 1993 establece:

Para efecto del artículo 267 de la Constitución Nacional se entiende por control posterior la vigilancia de las actividades, operaciones y procesos ejecutados por los sujetos de control y de los resultados obtenidos por los mismos. Por control selectivo se entiende la elección mediante un procedimiento técnico de una muestra representativa de recursos, cuentas, operaciones o actividades para obtener conclusiones sobre el universo respectivo en el desarrollo del control fiscal. [Énfasis añadidos.] (Congreso de la República, 1993a)

Posteriormente, la Corte Constitucional ha venido profundizando sobre los límites y alcances del control posterior y selectivo. Así, ha dicho que

La tarea de ente como las contralorías no es la de actuar dentro de los procesos internos de la administración cual si fueran parte de ella, sino precisamente la de ejercer el control y la vigilancia sobre la actividad estatal, a partir de su propia independencia, que supone también la del ente vigilado, sin que les sea permitido participar en las labores que cumplen los órganos y funcionarios competentes 
para conducir los procesos que después habrán de ser examinados desde la perspectiva del control. De lo contrario, él no podría ejercerse objetivamente, pues en la medida en que los entes controladores resultaran involucrados en el proceso administrativo específico, objeto de su escrutinio, y en la toma de decisiones, perderían toda legitimidad para cumplir fiel e imparcialmente su función. Así, pues, en tratándose de la Contraloría General de la República, el control a ella asignado es de carácter posterior, por expresa disposición del artículo 267 de la Constitución, motivo por el cual resulta evidente que a dicho órgano le está vedado participar en el proceso de contratación. Su función empieza justamente cuando la administración culmina la suya, esto es, cuando ha adoptado ya sus decisiones. [Énfasis añadido.] (Sentencia C-113, 1999, p. 1)

Sin embargo, en aras de aclarar y profundizar en la definición de procesos administrativos culminados o ejecutados para establecer el momento en el cual se puede iniciar el control posterior, el alto tribunal constitucional ha establecido que

[...] el control sobre los contratos estatales liquidados o terminados no es el único momento en que se lleva a cabo el control fiscal, dado que este puede efectuarse a partir de su legalización y durante su ejecución; (2) el control posterior no es en sí mismo inoportuno, pues este debe iniciarse una vez ejecutadas las operaciones o procesos objeto de control y antes de que prescriban las acciones correspondientes. [Énfasis añadido.] (Sentencia C-103, 2015, p. 28)

\section{LOS LÍMITES DEL CONTROL FISCAL POSTERIOR}

Pese a que el control fiscal posterior y selectivo se presentó como un gran avance y una necesidad fundamental para la modernización del sistema de control fiscal colombiano, a los pocos años de funcionamiento los límites del control posterior ya recibían críticas por parte de los representantes de los organismos de control fiscal, quienes promovieron e impulsaron acciones para ampliar su margen de acción. De este modo, el 22 de febrero del 2000, por medio del Decreto Ley 267 se dictaron normas sobre la organización y funcionamiento de la Contraloría General de la República, se estableció su estructura orgánica, se fijaron las funciones de sus dependencias y se dictaron otras disposiciones, entre ellas, sus funciones. 
El artículo 5 de la citada norma asignó nueve funciones a la Contraloría General de la República para cumplir su misión y sus objetivos. Entre ellas, fijo la siguiente: "Advertir sobre operaciones o procesos en ejecución para prever graves riesgos que comprometan el patrimonio público y ejercer el control posterior sobre los hechos así identificados" (Contraloría General de la República, 2000). Dicha disposición estuvo vigente por más de 15 años hasta que la Corte Constitucional la declaró contraria a los límites establecidos al control fiscal por la carta política de 1991: sin embargo, durante este periodo la figura de la advertencia y su extensión (prevención y actuación oportuna) fue motivo de debate y de propuestas por parte de los contralores.

Estas se presentaron de manera más sistemática y permanente a partir del 2010, a instancias del Contralor Julio César Turbay Quintero, quien propuso, entre otras cosas, regular la función preventiva "de naturaleza posterior y selectiva, superando la simple actuación cuando el daño patrimonial ya se ha causado, en beneficio de la protección colectivo de los recursos públicos" (Contraloría General de la República, 2010, p. 23).

Años después, el contralor Edgardo Maya (2014-2018) propuso el desarrollo de un control fiscal "oportuno":

Se hace evidente la necesidad de impulsar un sustancial cambio de enfoque que se caracterice por promover, desde el control real, oportuno, posterior y selectivo, una cultura de mejora en la rentabilidad social de los productos a cargo de los sujetos públicos y privados que son titulares de la gestión de recursos y bienes públicos. (Contraloría General de la República, 2015, p. 15)

Sin embargo, el mismo año que el contralor Maya propuso el cambio de enfoque, la Corte Constitucional se pronunció sobre la citada norma del 2000. El 11 de marzo, el alto tribunal privó a la Contraloría General de la República de su función de advertencia, consagrada en el numeral 7, del artículo 5 del Decreto Ley 267 del 2000. La función de advertencia había sido definida por la Contraloría de la siguiente manera:

[La función de advertencia es] una función excepcional que deviene de la atribución marco de vigilancia de la gestión fiscal, sin que la misma constituya un sistema de control fiscal propio del ejercicio posterior y selectivo a la gestión fiscal, en donde se concreta y materializan en estricto rigor constitucional 
nuestros pronunciamientos o dictámenes; de ahí que la oportunidad que la preceptiva indica para su ejercicio, en momento anterior a la emisión de los dictámenes producto del ejercicio auditor. En este orden, la filosofía de la función de advertencia radica en poner de presente al gestor fiscal, frente a procesos u operaciones en ejecución, la evidencia de un posible riesgo futuro que pueda causar detrimento al patrimonio estatal, para que si lo considera adopte de inmediato las acciones correctivas que la situación amerita, sin perjuicio del examen o revisión que le corresponde al Órgano de Vigilancia y Control Fiscal dentro de las atribuciones de su natural competencia, es decir, una vez concluidos los procesos u operaciones de la administración. [Énfasis añadido.] (Contraloría General de la República, 2007, folio 8)

Según la corporación, la intención del constituyente fue eliminar el sistema previo ejercido de manera extendida en el control fiscal e instaurar un sistema posterior y selectivo y, así mismo, prohibir a la Contraloría funciones administrativas distintas de las inherentes a su propia organización para evitar la coadministración y garantizar así no solo su independencia, sino una administración pública eficiente (Corte Constitucional, 2015).

En ese sentido, la Corte distingue dos tipos de control: el externo, ejercido por la Contraloría General de la República, la Auditoría General de la República y las contralorías territoriales, y el interno, efectuado por las propias entidades públicas. $\mathrm{Al}$ respecto, de manera previa el máximo tribunal había señalado:

no puede interpretarse como extendida a la posibilidad [de la Contraloría General de la República] de intervenir en los mecanismos de control interno que adopte la administración para el logro de sus objetivos, por cuanto, estaría de este modo interviniendo indirectamente en funciones de coadministración que le están prohibidas (art. 268 numeral 12 C.N.), sino como un poder de armonización y diseño de los sistemas de control atribuido a las instituciones, a cuyo cargo se encuentra el control fiscal y de resultado externo consagrado en la Constitución Política. (Corte Constitucional, 1993)

El texto demandado incluía una intervención de la Contraloría con carácter previo a la adopción de decisiones y la culminación de los procesos y operaciones 
administrativas, diferente del control posterior que se puede ejercer una vez la actuación administrativa haya culminado, no en términos de liquidez contractual, sino en razón de la formalización legal del procedimiento.

La formulación de advertencias supone, por definición, un llamado de atención que tiene el declarado propósito de intervenir, antes de que se adopten las decisiones administrativas o concluya la ejecución de los procesos de gestión fiscal, para evitar que se produzca o consume un daño al patrimonio público. En consecuencia, se trata de una modalidad no de simple vigilancia sino de control fiscal, que ha de someterse, por tanto, a los límites constitucionales que enmarcan el ejercicio legítimo de este último. (Corte Constitucional, 2015)

La advertencia, por tanto, era una modalidad de control fiscal ex ante y que contiene, además, una "capacidad de incidir en las decisiones y en el curso de los procesos y operaciones de las autoridades administrativas sometidas a vigilancia" (Corte Constitucional, 2015), en la medida en que pueda transformarse el curso de la acción. Esto podría entenderse como favorable en tanto pueda impedir que se consuma un detrimento patrimonial del Estado, pero, a su vez, afectaría la independencia de la auditoría que se ha de realizar porque esta podría estar viciada por la intervención previa que había hecho.

En virtud de lo anterior, las funciones de advertencia que podía ejercer la Contraloría General de la República fueron asumidas por el control interno de las autoridades públicas, que eran las llamadas a generar los mecanismos idóneos para prevenir que la gestión fiscal no fuera eficiente, económica, equitativa ni eficaz y que no tuviera en cuenta la valoración de los costos ambientales.

Para subsanar esta ausencia normativa que impedía ejercer la función de alerta, el actual contralor, Carlos Felipe Córdoba, propuso una reforma constitucional para que el control fiscal fuera, además de posterior y selectivo, concomitante y preventivo. Este tiene como propósito "el acompañamiento preventivo a los funcionarios durante la ejecución del recurso", con lo que se recupera la función de advertencia (CGR, 2019, p. 28). 


\section{EL CONTROL CONCOMITANTE Y PREVENTIVO: ACTO Legislativo 4 DEL 2019}

El contralor general de la República presentó un proyecto de acto legislativo que, entre otros aspectos, buscaba el desarrollo de un control fiscal concomitante y preventivo, complementario al control posterior y selectivo. Esta propuesta se presentó como una fórmula de solución a uno de los problemas de la corrupción: identificar los daños al erario público antes de que estos se hubieran materializado:

Una de las mayores críticas a las que se ha enfrentado el actual sistema, corresponde a que el ente de control solo actúa después de la ocurrencia del daño; es decir, cuando este se ha materializado, lo que implica en muchas ocasiones que, en contratos o ejecuciones plurianuales, el ente de control deba permanecer inerte, mientras el dańo al patrimonio tiene lugar y se consolida. (Córdoba, 2019)

$\mathrm{Al}$ aplicar un proceso de minería de datos de la exposición de motivos, se denota en el gráfico 1 que las principales frases demuestran la necesidad de fortalecer el control fiscal a través de un nuevo modelo que sea concomitante y preventivo.

Con esta frecuencia, se denota la relevancia en materia de propuestas que la Contraloría le otorgó a la reforma constitucional en materia de control fiscal. Pese a que el Proyecto de Acto Legislativo abordó un amplio número de modificaciones y temas, en este artículo solo se profundiza en el cambio en el modelo de control fiscal (concomitante y preventivo), en la medida en que se pretende trazar la trayectoria de este aspecto desde la Constitución hasta la actualidad.

Una de las adiciones que se le hicieron al proyecto, en relación con su mandato concomitante y preventivo, fue la inclusión de la siguiente frase en el artículo segundo: "Este control concomitante y preventivo será realizado en forma de advertencia al gestor fiscal y deberá estar incluido en un sistema general de advertencia que deberá ser público" (Senado de la República, 2019a, p. 9).

Esta demanda de necesaria trasformación del sistema de control fiscal no fue exclusiva de la Contraloría, y también se sumó a ella el órgano de control de segundo nivel: 
la Auditoría General de la República. Así, el auditor Carlos Hernán Rodríguez enfatizó en la ineficiencia del modelo posterior y selectivo, al considerar que los organismos de control de orden fiscal no pueden reaccionar en tiempo real a las denuncias ciudadanas ni a las evidencias que a todas luces podrían demostrar en un modelo preventivo y concomitante posibles hallazgos fiscales.

Gráfico 1. Frases con mayor frecuencia en la exposición de motivos del Acto Legislativo 4 del 2019

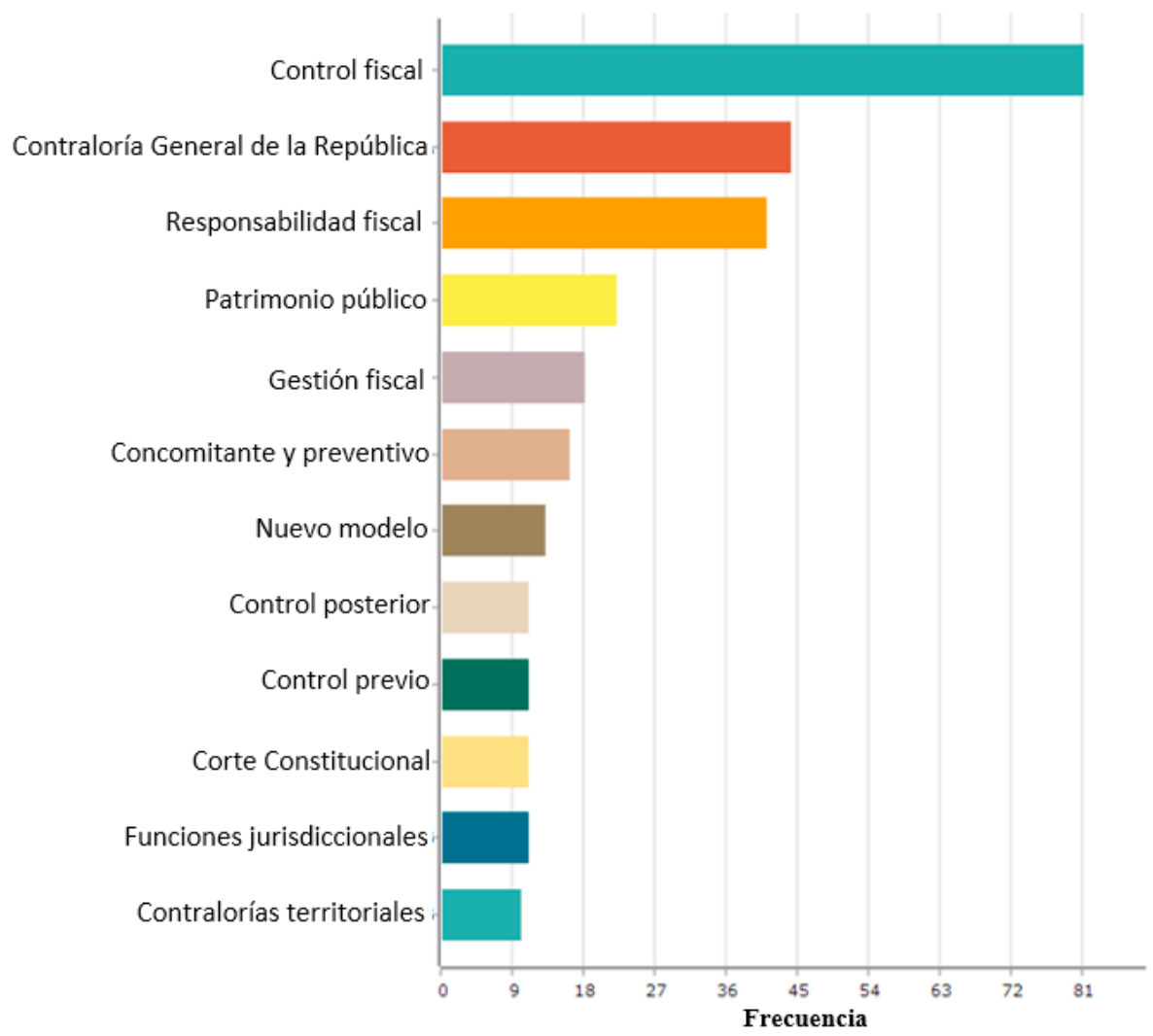

Fuente: elaboración propia con WordStat. 
El nuevo sistema se edifica sobre dos procesos: temporal y formal. El primero se refiere al momento en el cual el órgano de control puede intervenir para evitar que se cause un daño a la nación. El segundo, por su parte, se refiere a que esta intervención se ejecute solo cuando exista un riesgo inherente a la gestión; es decir, "aquel al que se enfrenta la entidad en ausencia de acciones por parte de la Dirección para modificar su probabilidad o impacto" (Departamento Administrativo de la Función Pública, 2011, p. 32). En ese sentido, el componente formal impide que el control se convierta en previo, dado que no sería sobre el universo de actuaciones administrativas como se desarrolla la gestión fiscal, sino sobre aquel en el que se identifique un riesgo inherente, es decir, actual (Blanco, 2015).

En este sentido, el acto legislativo revivió la función de advertencia, eliminada del ordenamiento jurídico en el 2015. Como sustento de esta necesidad, la Contraloría presentó el impacto de este instrumento durante la vigencia 2006-2015:

Tabla 1. Formulación de funciones de advertencia comparativa entre vigencias

\begin{tabular}{|c|c|c|c|}
\hline Vigencia & $\begin{array}{l}\text { Número de } \\
\text { funciones }\end{array}$ & Cuantía & $\begin{array}{l}\text { Porcentaje de } \\
\text { participación }\end{array}$ \\
\hline 2006 & 8 & 3159652019 & 0,0 \\
\hline 2007 & 30 & 407787870696 & 2 \\
\hline 2008 & 64 & 1600878712709 & 6,24 \\
\hline 2009 & 62 & 502895509801 & 2 \\
\hline 2010 & 144 & 860834890520 & 3,35 \\
\hline 2011 & 171 & 1512800402747 & 6 \\
\hline 2012 & 328 & 4832363349130 & 18,82 \\
\hline 2013 & 322 & 2683928749413 & 10 \\
\hline 2014 & 417 & 13267017914608 & 51,68 \\
\hline 2015 & 3 & 0 & 0 \\
\hline Totales & 1549 & 25671667051643 & 100 \\
\hline
\end{tabular}

Fuente: Carlos Felipe Córdoba. Exposición de motivos proyecto de acto legislativo. Bogotá: Contraloría General de la República, 2019, p. 5. 
Tabla 2. Formulación de funciones de advertencia comparativa entre vigencias

\begin{tabular}{lrc} 
Dependencia & \multicolumn{1}{c}{ Cuantía } & Porcentaje de participación \\
\hline $\begin{array}{l}\text { Contraloría delegada sector } \\
\text { agropecuario }\end{array}$ & 918174003716 & 3,58 \\
\hline $\begin{array}{l}\text { Contraloría delegada sector social } \\
\text { Contraloría delegada gestión pública }\end{array}$ & 2267340784006 & 9 \\
\hline Contraloría delegada infraestructura & 3430122718871 & 10,30 \\
\hline Contraloría delegada sector defensa & 9224859656485 & 13 \\
\hline Contraloría delegada medio ambiente & 198886792153 & 35,93 \\
\hline Contraloría delegada de minas & 2076860005871 & 1 \\
\hline Regalías & 63764682854 & 8,09 \\
\hline Gerencias departamentales & 4846755698848 & 18,88 \\
\hline Totales & $\mathbf{2 5 6 7 1 6 6 7 0 5 1 6 4 3}$ & $\mathbf{1 0 0}$ \\
\hline
\end{tabular}

Fuente: Carlos Felipe Córdoba. Exposición de motivos proyecto de acto legislativo. Bogotá: Contraloría General de la República, 2019. p. 6.

El desarrollo de estos dos modelos (posterior, selectivo y concomitante y preventivo), no conlleva, según la Contraloría, simultaneidad, sino complementariedad, y su aplicación no implica de manera alguna intromisión en la administración.

Esta propuesta fue recibida con beneplácito en el poder legislativo, que aprobó en poco tiempo el articulado que reforma la Constitución. Uno de los ponentes fue el senador Roy Barreras, quien afirmó:

El eje del articulado es otorgarle a la Contraloría la capacidad de un control preventivo y concomitante $[\ldots]$ que permita además una vez decidida la ejecución de los proyectos, acompañar a los alcaldes, los gobernadores, los coordinadores del gasto en una correcta ejecución para poder mejorar las cifras de eficiencia de los entes de control que hoy están apenas en el 0,6\%. (Senado de la República, 2019b)

Otra de las características del control preventivo es que no es vinculante, es decir, que, al funcionar como advertencia, esta no resulta obligatoria para la entidad que 
ejecuta o administra los recursos públicos, pues de lo contrario caería en la figura de la coadministración y, por tanto, del control previo (Quiroz, 2014).

Es importante resaltar, sin embargo, que el control posterior no significa que los procesos de auditoría y los posibles hallazgos fiscales puedan realizarse solo cuando el contrato haya finalizado (Sarmiento, Medina y Plazas, 2017). Es decir, el control posterior no implica que la actuación de las contralorías deba ser extemporánea. La Corte Constitucional ha sido enfática en ello:

Por el contrario, a la luz del principio de interpretación conforme, debe entenderse que el control fiscal comienza desde el momento mismo en que una entidad o un particular disponen de fondos oficiales; incluye el proceso de manejo e inversión; y se proyecta también en la evaluación de los resultados obtenidos con la utilización de esos recursos de acuerdo con el grado de realización de los objetivos trazados, es decir, con posterioridad a la finalización y liquidación de los contratos estatales. (Corte constitucional, 2012)

\section{ConClusión}

El desarrollo de un control preventivo no sería una de las principales necesidades que el país tuviese en materia de lucha contra la corrupción, si los procesos de control interno de las autoridades cumplieran de manera íntegra, oportuna y expedita lo que la Constitución y la ley les ordenan. El sistema de control interno, según la Ley 87 de 1993, se define como:

[E]1 sistema integrado por el esquema de organización y el conjunto de los planes, métodos, principios, normas, procedimientos y mecanismos de verificación y evaluación adoptados por una entidad, con el fin de procurar que todas las actividades, operaciones y actuaciones, así como la administración de la información y los recursos, se realicen de acuerdo con las normas constitucionales y legales vigentes dentro de las políticas trazadas por la dirección y en atención a las metas u objetivos previstos. El ejercicio del control interno debe consultar los principios de igualdad, moralidad, 
eficiencia, economía, celeridad, imparcialidad, publicidad y valoración de los costos ambientales. (Congreso de la República, 1993b)

El diseño de este sistema está pensado para que pueda prevenir y detectar de manera oportuna el mal uso de los recursos públicos y la corrupción correspondiente, de ahí que la función preventiva y concomitante a la que ahora están llamados los organismos de control es la que tiene como misión el control interno de las entidades. De ahí que se resalte la importancia del Departamento Administrativo de la Función Pública en la prevención de la corrupción o de la gestión fiscal ineficiente e ineficaz, dado que es el organismo rector en materia de política de control interno, y es el llamado a exigir la puesta en práctica de medidas correctivas ante las falencias de aplicación de ese sistema (Contraloría General de la República, 2011).

El fortalecimiento del Sistema de Control Interno sigue siendo una necesidad imperante y una deuda pendiente de las autoridades para afrontar los problemas de la administración pública a través de oportunos planes de mejoramiento.

\section{REFERENCIAS}

Asamblea Nacional Constituyente (1991). Constitución política de Colombia. Artículo 267. Asamblea Nacional Constituyente (9 de mayo de 1991). Informe de la sesión de la Comisión Quinta. Gaceta Constitucional. Colombia.

Blanco, C. (2013). Aproximación a la noción de soberanía estatal en el marco del proceso andino de integración. Revista Republicana, 15. Recuperado de http://ojs.urepublicana. edu.co/index.php/revistarepublicana/article/view/23

Blanco, C. (2015). La influencia positiva de la CAN en la descentralización territorial colombiana. Revista Opinión Jurídica, 14(27). Recuperado de https://revistas.udem.edu.co/ index.php/opinion/article/view/1204

Congreso de la República de Colombia (1993a). Ley 42 de 1993.

Congreso de la República de Colombia (1993b). Ley 87 de 1993.

Contraloría General de la República (2007). Circular n. 005. Bogotá: Contraloría. 
Contraloría General de la República (2010). Una gestión fiscal ética y eficiente: así cumplimos. Bogotá: Contraloría.

Contraloría General de la República (2011). Informe concepto del sistema de control interno. Bogotá: Contraloría.

Contraloría General de la República (2019). Informe de gestión al Congreso y al Presidente de la República. Una contraloría para todos. Bogotá: Contraloría.

Córdoba, C. F. (2019). Exposición de motivos proyecto de acto legislativo. Bogotá: Congreso de la República.

Corte Constitucional (11 de noviembre de 1993). Sentencia C-534. [M. P. Fabio Morón Díaz].

Corte Constitucional (24 de febrero de 1999). Sentencia C-113. [M. P. José Gregorio Hernández Galindo].

Corte Constitucional (21 de noviembre del 2012). Sentencia C-967. [M. P. Jorge Iván Palacio Palacio].

Corte Constitucional (11 de marzo de 2015). Sentencia C-103. [M. P. María Victoria Calle Correa].

Departamento Administrativo de la Función Pública (2011). Guía para la administración del riesgo. Bogotá: DAFP.

González, A. (2018). Fundamentos constitucionales de la política de control fiscal. En M. Moya (coord.). Trayectoria de la politica de control fiscal. Bogotá: Auditoría General de la República.

González, A. (2019). Principios Constitucionales de la gestión fiscal: condiciones esenciales para garantizar los derechos fundamentales. En M. Moya (Coord.), Presupuestos para la construcción de una politica pública del control fiscal (pp. 14-29). Bogotá: Auditoría General de la República.

González, O. (2016). La omisión legislativa como hecho generador de la responsabilidad patrimonial del Estado. Revista Verba Iuris, ed. n. ${ }^{\circ}$ 35. Recuperado de https://revistas. unilibre.edu.co/index.php/verbaiuris/article/view/5/2

Noriega, C., Gonzalez, J. y Herrán, H. (18 de abril de 1991). Informe de la comisión quinta de hacienda pública y presupuesto. Gaceta constitucional. Bogotá. 
Pavas, D. (2010). La Misión Kemmerer y el control estatal. Apuntes contables, (12), 79-90.

Presidencia de la Republica (22 de febrero del 2000). Decreto 267 del 2000.

Quiroz, M. (2014). Acercamiento a las “oposiciones paradigmáticas” entre neoconstitucionalismo y positivismo jurídico en Revista Iusta, 41(2), 77-97.

Rodríguez, A. (2014). Indicadores de constitucionalidad de las políticas públicas: enfoque de gestión de derechos. Via Inveniendi et Iudicandi, 9(2), 45-78

Sarmiento, D., Medina, S. y Plazas, R. (julio-diciembre del 2017). Sobre la responsabilidad y su relación con el daño y los perjuicios. Via inveniendi et Iudicandi, 12(2), 101-115. doi: http://dx.doi.org/10.15332/s1909-0528.2017.0002.04

Senado de la República (2019). Gaceta del Congreso 360. Bogotá: Congreso.

Senado de la República. Comisión Primera (2019). Gaceta del Congreso n. ${ }^{\circ} 477$. Bogotá: Congreso.

Uprimny, R. (2011). Las trasformaciones constitucionales recientes en América Latina: tendencias y desafíos. En C. Rodríguez Garavito. El derecho en América Latina: un mapa para el pensamiento jurídico del siglo XXI. Buenos Aires: Siglo XXI. 